\title{
'Omics' and Chemical Approaches Used to Monitor Iron-Deficiency in
}

\section{Citrus Rootstocks}

Concetta Licciardello1,*, Vera Muccilli2, Biagio Torrisi1, Paola Tononi3, Debora Fontanini4, Maria Allegra1, Fabiola Sciacca1, Salvatore Foti2, Massimo Delledonne3, Francesco Intrigliolo1 and Giuseppe Reforgiato Recupero1

1Consiglio per la Ricerca e la Sperimentazione in Agricoltura (CRA-ACM), Acireale, Italy

${ }_{2}$ Dipartimento di Biotecnologie, Università di Verona, Verona, Italy

3Dipartimento di Scienze Chimiche, Università di Catania, Catania, Italy

4Dipartimento di Biologia, Università di Pisa, Pisa, Italy

*Corresponding author: concetta.licciardello@entecra.it

\begin{abstract}
Two different 'omics' approaches were performed to a better comprehension of biological mechanisms involved in citrus iron $(\mathrm{Fe})$ deficiency. Tips roots from Swingle citrumelo and Carrizo citrange (sensitive and tolerant rootstocks, respectively), growing in pots with control and chlorotic soil, were used for transcriptomic and proteomic analysis. CombiMatrix array was performed to isolate differential genes, among which glutathione peroxidase (GPX), SAUR gene and glutamate dehydrogenase (GDH) showed to be the most involved ones. They were switched on Swingle grown on calcareous conditions compared to Carrizo (in the same soil) and to the same stock in the control soil. The over-expression of GPX could be the effort of plants to neutralize the oxidative environment produced by stress. The involvement of auxin (and as consequence of SAUR gene) in the regulation of Fe deficiency responses is also well known. Both genes were considered in association to peroxidase, ferric chelate reductase activities, iron and chlorophyll content, to monitor the degree of suffering of rootstocks. Among differentially expressed proteins, identified by means of 2D-PAGE and RP-HPLC/nESI-MSMS, a strong down-regulation of cytosolic pyrophosphate-dependent phosphofructokinase $\beta$-subunit and NADPH-isocitrate dehydrogenase could produce plant inability to sustain the energetic request of cell roots.
\end{abstract}

Keywords: transcriptomic, proteomic, microarray, calcareous soil, Swingle, Carrizo 


\section{INTRODUCTION}

At least 20 to $50 \%$ of fruit trees in the Mediterranean Basin suffer from iron (Fe) deficiency (Jaegger et al., 2000), caused by high concentrations of calcium and bicarbonate in the soil. Although $\mathrm{Fe}$ is quite abundant in the Earth, it is often a limiting resource for plant's growth, due to its low availability (Guerinot and Yi, 1994) and to the scarce solubility in well-aerated environments (Donnini et al., 2010). This condition affects metabolic processes of leaves and roots, reducing the availability of $\mathrm{Fe}$ for the plant (Mengel, 1994) and inducing the development of symptoms of Fe chlorosis. The most common symptoms consist of interveinal chlorosis in young leaves (Morales et al., 1998), decrease in leaf net photosynthetic rate (Briat et al., 1995), leaves reduced in size, fragile and very thin, growth retardation of the plant, stasis followed by death in more severe conditions. In these cases, Fe deficiency causes the loss of yield (Pestana et al., 2003), delayed fruit ripening, and impaired fruit quality, as reported in peach (Sanz et al., 1997) and orange (Pestana et al., 2011). Severe reductions of yield were associated with a decrease in leaf chlorophyll concentration in peach, kiwifruit, and pear growing in calcareous soils (Rombolà et al., 1999). There are two main different systems to recover plants affecting Fe deficiency. The first is a chemical approach, consisting in the use of inorganic Fe salts, synthetic chelates and natural organic compounds. The second approach consists in the use of tolerant rootstocks. Considering that fertilizers are quite costly and pollutant for the soil, the easiest way to avoid Fe chlorosis from calcareous soils in fruit trees is through the use of tolerant rootstocks. The Citrus genus is considered to be susceptible to Fe chlorosis (Carpena-Artes et al., 1995) and its tolerance/sensitivity is determined by the rootstock. Sour orange (Citrus aurantium) was the most used rootstock, considering also his tolerance to Fe deficiency, but unfortunately it is sensitive to Citrus Tristeza Virus (CTV) and for this reason it was replaced by virus-tolerant genotypes. In this sense, the search for alternative rootstocks, such as hybrids derived from Poncirus trifoliata, is the main strategy to conciliate the tolerance to Fe deficit and to CTV. However, large phenotypic variations exist among different rootstocks, in particular Swingle citrumelo $(C$. paradisi $\times$ P. trifoliata $)$ is considered very susceptible to Fe deficit, while Carrizo citrange $(C$. sinensis $\times P$. trifoliata $)$ is quite tolerant (Hamze et al., 1986).

We present a transcriptomic and a proteomic approach, whose experimental design allowed the isolation of stress-specific and species-specific genes/proteins. Plants of Swingle and Carrizo grown in pots with a controlled and calcareous soil were considered for the analysis. These data were compared to chemical analyses such as the measurement of photosynthesis, chlorophyll content and peroxidase activity in leaves, and ferric chelate reductase activity in roots. Differential expression 
genes were validated on roots of plants grown on an experimental field with a naturally calcareous soil.

\section{MATERIALS AND METHODS}

\section{Plant Material and Chemical Activities}

Seedlings of Swingle and Carrizo were grafted with Tarocco Scirè sweet orange. Trees were grown for three years in plastic pots containing volcanic ( $\mathrm{pH}$ 6.3) and calcareous ( $\mathrm{pH}$ 8.7) soil. Tip roots of $5 \mathrm{~mm}$ in length were collected from three biological replicates for each rootstock grown in a selected soil. The same samples were used for transcriptomic, proteomic and chemical analyses. The degree of tolerance of Fe deficiency was evaluated determining root FCR activity, according to Welch et al. (1993) and Albano and Miller (1996). Leaf greenness was monitored by a portable SPAD-502 chlorophyll meter (Minolta, Osaka, Japan). The SPAD readings were evaluated according to Intrigliolo et al. (2000). Leaf chlorophyll concentration was determined as a sum of chlorophyll a and b at 663 and $645 \mathrm{~nm}$. The peroxidase activity was evaluated on young leaves according to Ngo and Lenhoff (1980). The same chemical analysis on leaves and roots were also performed on the field (Table 1). Table 1. SPAD, iron, chlorophyll content, POD in leaves and ferric-chelate reductase in roots of Swingle citrumelo and Carrizo citrange both in pots and in field trial.

\section{Total RNA Extraction and Expression Analysis}

Total RNA was extracted from $0.1 \mathrm{~g}$ of root tips from each biological replicate using the SpectrumTM Plant Total RNA Kit (Sigma). The same RNA was used for chip hybridization and for Real time RT-PCR experiments to validate differential data. The total RNA, from three biological replicates of Swingle and Carrizo grown in the experimental farm, was also extracted from $0.1 \mathrm{~g}$ of roots tips and leaves (RNase Plant Mini kit, Qiagen) and from $3 \mathrm{ml}$ of orange juice (Ancillo et al., 2007). All total RNAs were treated with DNase (Promega) for $30 \mathrm{~min}$ at $37^{\circ} \mathrm{C}$. The confirmation of differential data was performed using the Real time RT-PCR according to Licciardello et al. (2008).

\section{Microarray Analysis}

Expression analysis was performed on a custom 90K CombiMatrix microarray (CustomArray Inc, USA) containing around 8,000 specific probes of 35-40 bp in length designed using the OligoArray 2.1 software (Rouillard et al., 2003). Reverse transcription, amplification and labeling were performed with the RNA AmpULSe amplification and labeling kit according to manufacturer's 
instructions (Kreatech Diagnostics, The Netherlands). Five micrograms of the purified labeled aRNA (amplified RNA) was hybridized to the array according to the manufacturer's protocol. The array was scanned with an Axon GenePix 4400A scanner. Data extraction was performed using the GenePix Pro 7 software. Genes were considered significant when False Discovery Rate (FDR) was $\leq 0.05$ and $\log _{2}$ fold change was $\geq 0.66$ or $\leq-0.66$. Functional annotation was performed through Blast2GO software, using the BlastX algorithm and the nonredundant database.

\section{Proteomic Analysis}

Protein extraction was performed according to the phenol protocol described in Isaacson et al. (2006). 2D-electrophoresis separation was performed according to Muccilli et al. (2009). A total of thirty-six 2DE gels (three technical replicates for each of the three biological replicates per sample), were analyzed. The gel images were uploaded onto the Ludesi REDFIN3 software server ver. 3.3 rev. 2.0 to be analyzed with the Solo protocol (Lund, Sweden; http://www.ludesi.com). Among the statistically significant protein spots ( $\mathrm{p}<0.05$, ANOVA), only 219 significantly modulated protein spots ( $>1.5$ fold and $<0.66$ fold) were taken into consideration for MS analysis. Spots were analyzed by mass spectrometry according to Muccilli et al. (2009). MS/MS data were used to perform protein identifications by Mascot search engine version 2.3 (www.matrixscience.com) against NCBInr protein and ESTs databases. The assignment of putative roles into known eukaryotic biosynthetic pathways was performed using Swiss Prot (http://web.expasy.org/docs/swissprot_guideline.html) and bibliographic references.

\section{RESULTS}

\section{Stress-Specific and Specie-Specific Data}

The CombiMatrix platform, made up of around 8.000 of probes derived from STs of Citrus and various rootstocks roots retrieved from the NCBI database, was hybridized with RNAs isolated from roots tips of Swingle and Carrizo grown under volcanic and calcareous conditions in pots. The experimental design (Fig. 1) was performed with the aim to isolate stress-specific genes typical of the sensitive rootstock, considering the Swingle in calcareous conditions compared to Swingle in the volcanic soil and respect to Carrizo in calcareous conditions.

Data were then confirmed in a naturally calcareous soil in the field, which expression and chemical reported data refer to. 
The stress condition was also monitored on leaves, evaluating chemical activities, such as SPAD, Fe content, total chlorophyll and POD activity. Lower data in Swingle respect to Carrizo (Table 1) were a confirmation of suffering condition, as showed by leaves of stock.

Among all differential genes isolated using the microarray analysis most of them resulted unknown/unnamed. Among the remaining differentially expressed genes, only three were the most interesting and in particular they are specific of Swingle in calcareous soil when compared to Carrizo in volcanic soil. These genes are the glutathione peroxidase (GPX), the Small Auxin Up RNA (SAUR) family protein gene and the glutamate dehydrogenase (GDH). The expression of these genes was confirmed in the sampling carried out in experimental farm where soil is naturally and typically calcareous. The GPX is involved in the oxidative process. It is over-expressed in the sensitive rootstock (Fig. 2) as a defensive response to most metals which may cause damage or disturb normal function of the plants (Fang and Kao, 2000).

The SAUR family protein gene was an over-expressed genes in Swingle compared to Carrizo under Fe deficient conditions after the hybridization of the CombiMatrix platform. We pointed the attention on validating the differential expression also in roots of plants in the field (Fig. 2), because auxin is a hormone involved in the elongation of roots (Perry et al., 2007). Production of lateral root formation showed a well-structured organization in the Swingle respect to a more simplicity in the Carrizo rootstock.

Expression data were associated to chemical parameters, such as the ferric chelate reductase activity (Table 1), in which reduced values on sensitive rootstocks in pots and in plants of the field could be due to a greater necessity of sensitive rootstock to reduce $\mathrm{Fe}_{3+}$ to $\mathrm{Fe}_{2+}$, considering the necessity to induce the use of Fe from the soil. Among stress-specific genes, the GDH was down-expressed in Swingle in the calcareous soil compared to Carrizo in the same situation (Fig. 2). The overexpression of GDH, providing the effective functioning of the TCA cycle through the oxidation of glutamate, in the tolerant rootstock could be an indication of the ability of Carrizo to be energetically more active respect to Swingle (Robinson et al., 1991).

Although the transcriptomic approach resulted exhaustive for the isolation of stress-specific genes, we thought to strengthen these data using the proteomic support. It turned-out interesting for the identification of enzymes characterizing the rootstock, in particular the Carrizo compared to Swingle, mostly under Fe deficiency conditions. In our analysis the proteomic approach allowed the identification of glyceraldehyde-3-phosphate dehydrogenase, a glycolytic enzyme involved in the energetic metabolism, significantly over-expressed in Carrizo grown in Fe deficient conditions respect to the same rootstock in volcanic soil (Fig. 3a). In addition a phosphofructokinase $\beta$-subunit 
(involved in the glycolysis) and a cytosolic NADPH-isocitrate dehydrogenase (involved in the TCA cycle) resulted down-expressed in Swingle respect to Carrizo regardless the growing soil (Fig. $3 b)$.

\section{The Involvement of Aconitase Isoforms}

Fe deficiency is an abiotic stress condition that causes the delay of fruit ripening and impairs fruit quality. In particular, it is known that citrus fruits from plants in Fe deprivation conditions are more acidic respect to fruits from plants in Fe-sufficient conditions (Shlizerman et al., 2007). The main gene involved in the acidification process is the aconitase, which transforms the citrate in isocitrate. In Terol et al. (2010) a classification of the three main important aconitase isoforms in clementine is described.

Expression analysis of different isoforms and various acid/not acid citrus varieties allowed to the identification of Aco1 and Aco2 as the main isoforms involved in the fruit acidification process. In our work, the expression analysis of the three isoforms of aconitase was performed on juice sacs of Swingle and Carrizo fruits, with the evidence of a no involvement of Aco3, confirming data previously reported (Terol et al., 2010).

Real time RT-PCR data showed a higher expression of Aco 2 in the sensitive respect to the tolerant rootstock (Fig. 4), in a significant way respect to the Aco1 (data not reported). These data are perfectly in accordance with acidity of fruits (Licciardello et al., 2013),confirming the relation between the expression and the acidification process. In roots after the hybridization of the CombiMatrix array an aconitase was also isolated as downexpressedin Swingle respect to Carrizo. The Real time RT-PCR confirmed the downexpression of this aconitase in roots of plants in pots and in the experimental field (data not shown), assuming the same trend of the isoform 3 of aconitase (Fig. 4).

\section{DISCUSSION}

Fe deficiency is an abiotic stress condition well studied in various plants species, such as citrus (Forner-Giner et al., 2010), tomato (Zamboni et al., 2012), soybean (O’Rourke et al., 2007), cucumber (Donnini et al., 2010), apple (Wang et al., 2010) and beet (Rellán-Álvarez et al., 2010). Fe deficiency has an impact not only in production but also in fruits quality. A double approach, transcriptomic and proteomic, was used to study the Fe deficiency in citrus, with the aim to isolate stress-specific and specie-specific genes/proteins. The hybridization of a CombiMatrix platform allowed the isolation of stress-specific genes, such as GPX, SAUR gene and 
GDH. Generally stress induces the production of ROS, to which plant face through the synthesis of antioxidant enzymes such as GPX. The over-expression of GPX in Swingle could be explained as the attempt that the sensitive rootstock does to neutralize the oxidative cloud produced by the $\mathrm{Fe}$ deficiency. Similarly, the higher expression of SAUR gene elucidates the possible role of auxin as an upstream signal in modulating Fe deficiency responses in dicots (Chen et al., 2010). Also the morphological alterations resembling developmental responses to Fe deficiency are well documented (Schmidt et al., 2003). Thus, the transcriptomic approach was useful in the isolation of stress-specific genes, involved in the protection against the oxidative stress and in the absorption of Fe through the elongation of roots.

Proteomic analysis allowed the identification, in Carrizo grown in calcareous soil respect to the volcanic one, of an over-expressed enzyme (glyceraldehyde-3-phosphate dehydrogenase) devoted to energy production that may explain the ability of this rootstock to react to stress conditions. In addition, the identification of phosphofructokinase $\beta$-subunit (involved in glycolysis) and a cytosolic NADPH-isocitrate dehydrogenase (involved in the TCA cycle), as over-expressed enzymes in Carrizo respect to Swingle, regardless from the soil condition, are consistent with previous observations (Muccilli et al., 2013), which showed that several cytosolic dehydrogenases from the glycolytic and pentose phosphate pathways, are enhanced under Fe deficiency. Therefore, the lower abundance of these enzymes may be related to the reduced adaptability of Swingle to Fe deficient conditions. Moreover, when citrus plant are subjected to prolonged stress periods, fruits tend to be more acidic respect to the fruits of healthy plants. In the present study, an expression analysis of selected members of the aconitase gene family was performed on fruits and on root tips of Swingle and Carrizo rootstocks. We confirmed the involvement of the isoform 2 in the acidification of fruits, as reported by Terol et al. (2010), assuming that the sensitive rootstock produces fruits more acid respect to the tolerant one. The opposite trend between Aco 2 in juice sacs (higher in Swingle compared to Carrizo) and Aco3 in roots (in which the expression is higher in Citrumelo respect to Swingle) could be the effect of different cellular compartment in which they are involved: in particular Aco2 is mitochondrial and Aco3 is cytosolic form (Hortschansky et al., 2007; Shlizerman et al., 2007).

\section{Literature Cited}

1. Albano, J.P. and Miller, W.B. 1996. Iron deficiency stress influences physiology of iron acquisition in marigold (Tagetes erecta L). J. Am. Soc. Hort. Sci. 121:438-441. 
2. Ancillo, G., Gadea, J., Forment, J., Guerri, J. and Navarro, L. 2007. Class prediction of closely related plant varieties using gene expression profiling. J. Exp. Bot. 58:1927- 1933.

3. Briat, J.F., Fobisloisy, I., Grignon, N., Lobreaux, S., Pascal, N., Savino, G., Thoiron, S., von Wiren, N. and van Wuytswinkel, O. 1995. Cellular and molecular aspects of iron metabolism in plants. Biol. Cell. 84:69-81.

4. Carpena-Artes, O., Moreno, J.J., Lucena, J.J. and Carpena-Ruiz, R.O. 1995. Response to iron chlorosis of different hydroponically grown Citrus varieties. p.147-151. In: J. Abadía (ed.), Iron Nutrition in Soils and Plants. Kluwer Academic Publisher, The Netherlands.

5. Chen, W.W., Yang, J.L., Qin, C., Jin, C.W., Mo, J.H., Ye, T. and Zheng, S.J. 2010. Nitric oxide acts downstream of auxin to trigger root ferric-chelate reductase activity in response to iron deficiency in Arabidopsis. Plant Physiol. 154:810-819.

6. Donnini, S., Prinsi, B., Negri, A.S., Vigani, G., Espen, L. and Zocchi, G. 2010. Proteomic characterization of iron deficiency responses in Cucumis sativus L. roots. BMC Plant Biol. 10 .

7. Fang, W.C. and Kao, C.H. 2000. Enhanced peroxidase activity in rice leaves in response to excess iron, copper and zinc. Plant Sci. 158:71-76.

8. Forner-Giner, M.A., Llosa, M.J., Carrasco, J.L., Perez-Amador, M.A., Navarro, L. and Ancillo, G. 2010. Differential gene expression analysis provides new insights into the molecular basis of iron deficiency stress response in the citrus rootstock Poncirus trifoliata (L.) Raf. J. Exp. Bot. 61:483-490.

9. Guerinot, M.L. and Yi, Y. 1994. Iron: nutritious, noxious, and not readily available. Plant Physiol. 104:815-820.

10. Hamze, M., Ryan, J. and Zaabout, M. 1986. Screening of citrus rootstocks for lime-induced chlorosis tolerance. J. Plant Nutr. 9:459-469.

11. Hortschansky, P., Eisendle, M., Al-Abdallah, Q., Schmidt, A.D., Bergmann, S., Thon, M., Kniemeyer, O., Abt, B., Seeber, B., Werner, E.R., Kato, M., Brakhage, A.A. and Haas, H. 2007. Interaction of HapX with the CCAAT-binding complex - a novel mechanism of gene regulation by iron. Embo J. 26:3157-3168.

12. Intrigliolo, F., Giuffrida, A., Rapisarda, P., Calabretta, M. and Roccuzzo, G. 2000. SPAD as an indicator of nitrogen status in Citrus. In: Proc. Int. Soc. Citr. IX Congress (eds.) p.665667.

13. Isaacson, T., Damasceno, C.M.B., Saravanan, R.S., He, Y., Català, C., Saladie, M. and Rose, J.K.C. 2006. Sample extraction techniques for enhanced proteomic analysis of plant tissues. Nature Protocols 1:769-74. 
14. Jaegger, B., Goldbach, H. and Sommer, K. 2000. Release from lime induced iron chlorosis by CULTAN in fruit trees and its characterization by analysis. Acta Hort. 531:107-113.

15. Laemmli, U.K. 1970. Cleavage of structural proteins during the assembly of the head of batteriophage T4. Nature 227:680-685.

16. Licciardello, C., Russo, M.P., Valè, G. and Reforgiato Recupero, G. 2008. Identification of differentially expressed genes in the flesh of blood and common oranges. Tree Genet. Genom. 4:315-331.

17. Licciardello, C., Torrisi, B.F., Tononi, P., Allegra, M., Sciacca, F., Muccilli, V., Delledonne, M., Intrigliolo, F. and Reforgiato Recupero, G. 2013. Use of a root specific CombiMatrix array to evaluate gene expression analysis in sensitive and tolerant citrus rootstocks on chlorotic conditions. J. Am. Soc. Hort. Sci. 138(6):1-12.

18. Mengel, K. 1994. Iron availability in plant-tissues: iron chlorosis on calcareous soils. Plant Soil. 165: 275-283.

19. Morales, F., Abadía, A. and Abadía, J. 1998. Photosynthesis, quenching of chlorophyll fluorescence and thermal energy dissipation in iron-deficient sugar beet leaves, Austr. J. Plant Physiol. 25: 403-412.

20. Muccilli, V., Licciardello, C., Fontanini, D., Russo, M.P., Cunsolo, V., Saletti, R., Reforgiato Recupero, G. and Foti, S. 2009. Proteome analysis of Citrus sinensis L. (Osbeck) flesh at ripening time. J. Proteomics 73:134-52.

21. Muccilli, V., Licciardello, C., Fontanini, D., Cunsolo, V., Capocchi, A., Saletti, R., Torrisi, B. and Foti, S. 2013. Root protein profiles of two citrus rootstocks grown under iron sufficiency/deficiency conditions. Eur. J. Mass Spectr. 19:305-324.

22. Ngo, T.T. and Lenhoff, H.M. 1980. A sensitive and versatile chromogenic assay for peroxidase and peroxidase-coupled reactions. Anal. Biochem. 105:389-97.

23. O’Rourke, J.A., Charlson, D.V., Gonzalez, D.O., Vodkin, L.O., Graham, M.A., Cianzio, S.R., Grusak, M.A. and Shoemaker, R.C. 2007. Microarray analysis of iron deficiency chlorosis in near-isogenic soybean lines. BMC Genomics 8:476. doi:10.1186/1471-2164-8476.

24. Perry, P., Linke, B. and Schmidt, W. 2007. Reprogramming of root epidermal cells in response to nutrient deficiency. Biochem. Soc. Trans. 35:161-163.

25. Pestana, M., Correia, P.J., David, M., Abadía, A., Abadía, J. and de Varennes, A. 2011. Response of five citrus rootstocks to iron deficiency. J. Plant Nutr. Soil Sci. 174: 837- 846.

26. Pestana, M., de Varennes, A. and Faria, E. 2003. Diagnosis and correction of iron chlorosis in fruit trees: a review. J. Food Agric. Environ. 1:4 6-51. 
27. Rellán-Álvarez, R., Andaluz, S., Rodriguez-Celma, J., Wohlgemuth, G., Zocchi, G., Alvarez-Fernandez, A., Fiehn, O., Lopez-Millan, A.F. and Abadía, J. 2010. Changes in the proteomic and metabolic profiles of Beta vulgaris root tips in response to iron deficiency and resupply. BMC Plant Biol. 10:120. doi:10.1186/1471-2229-10-120

28. Rombolà, A.D., Quartieri, M., Marangoni, B., Tagliavini, M., Scudellari, D. and Abadìa, J. 1999. Strategie di cura della clorosi ferrica nella frutticoltura integrata. Frutticoltura 5: 5964.

29. Schmidt, W., Michalke, W. and Schikora, A. 2003. Proton pumping by tomato roots. Effect of Fe deficiency and hormones on the activity and distribution of plasma membrane $\mathrm{H}_{+-}$ ATPase in rhizodermal cells. Plant Cell Env. 26:361-370.

30. Shevchenko, A., Wilm, M., Vorm, O. and Mann, M. 1996. Mass spectrometric sequencing of proteins from silver-stained polyacrylamide gels. Anal Chem. 68:850-858.

31. Shlizerman, L., Marsh, K., Blumwald, E. and Sadka, A. 2007. Iron-shortage-induced increase in citric acid content and reduction of cytosolic aconitase activity in Citrus fruit vesicles and calli. Physiol. Plantarum 131:72-79.

32. Welch, R.M., Norvell, W.A., Schaefer, S.C., Shaff, J.E. and Kochian, L.V. 1993. Induction of iron(III) and copper(II) reduction in pea (Pisum satirum L.) roots by $\mathrm{Fe}$ and $\mathrm{Cu}$ status: Does the root-cell plasmalemma Fe(III)-chelate reductase perform a general role in regulating cation uptake? Planta 190: 555-561.

33. Zamboni, A., Zanin, L., Tomasi, N., Pezzotti, M., Pinton, R., Varanini, Z. and Cesco, S. 2012. Genome-wide microarray analysis of tomato roots showed defined responses to iron deficiency. BMC Genom. 13:101. doi: 10.1186/1471-2164-13-101 
Table 1. SPAD, iron, chlorophyll content, POD in leaves and ferric-chelate reductase in roots of Swingle citrumelo and Carrizo citrange both in pots and in field trial.

\begin{tabular}{|c|c|c|c|c|c|c|c|}
\hline & & & & Lea & ves & & Roots \\
\hline & & & SPAD index & $\begin{array}{c}\mathrm{Fe} \\
\left(\mathrm{mg} \mathrm{kg}^{-1}\right)\end{array}$ & $\begin{array}{c}\text { Chltot } \\
\left(\mathrm{mg} \mathrm{g}^{-1} \mathrm{FW}\right)\end{array}$ & $\begin{array}{l}\mathrm{POD} \\
\left(\mathrm{U} \mathrm{g}^{-1}\right. \\
\mathrm{FW})\end{array}$ & $\begin{array}{c}\mathrm{FCR} \\
{\left[\mathrm{Fe}^{2+}\left(\mu \mathrm{mol} \mathrm{g}{ }^{-1}\right.\right.} \\
\left.\left.\mathrm{h}^{-1} \mathrm{FW}\right)\right]\end{array}$ \\
\hline$\tilde{\sigma}$ & Rootstock & $\begin{array}{l}\text { Swingle } \\
\text { Carrizo }\end{array}$ & $\begin{array}{c}\text { n.s. } \\
44.87 \\
45.26\end{array}$ & $\begin{array}{l}\text { n.s. } \\
32.7 \\
38.1\end{array}$ & $\begin{array}{l}\text { n.s. } \\
1.45 \\
1.39\end{array}$ & $\begin{array}{c}\text { n.s. } \\
16.43 \\
17.22\end{array}$ & $\begin{array}{c}\text { n.s. } \\
0.041 \\
0.043\end{array}$ \\
\hline$\stackrel{0}{2}$ & Soil & $\begin{array}{l}\text { Calcareous } \\
\text { Volcanic }\end{array}$ & $\begin{array}{c}* \\
40.15 \\
49.98\end{array}$ & $\begin{array}{l}\text { n.s. } \\
33.2 \\
37.6\end{array}$ & $\begin{array}{c}* * \\
1.07 \\
1.76\end{array}$ & $\begin{array}{c}* * * \\
13.49 \\
20.16\end{array}$ & $\begin{array}{l}* * * \\
0.053 \\
0.031\end{array}$ \\
\hline$\stackrel{9}{9}$ & Rootstock & Swingle & $\begin{array}{l}* * * * \\
29.40\end{array}$ & $\begin{array}{c}* \\
32.9\end{array}$ & $\begin{array}{c}* * * \\
0.605\end{array}$ & $\begin{array}{c}* * \\
6.733\end{array}$ & $\begin{array}{c}* * * \\
0.099\end{array}$ \\
\hline 厌 & & Carrizo & 76.33 & 48.3 & 3.007 & 16.148 & 0.137 \\
\hline
\end{tabular}

SPAD index, iron $(\mathrm{Fe})$, total content of chlorophyll $\left(\mathrm{Chl}_{\mathrm{tot}}\right)$ and peroxidase actity (POD) were determined on leaves; ferric-chelate reductase (FCR) was determined on roots.

ANOVA $=* * * p \leq 0.001 ; * * p \leq 0.01 ; * p \leq 0.05$; absence of asterisk indicates absence of significance.

$\mathrm{FW}=$ fresh weight. 
Stress-specific

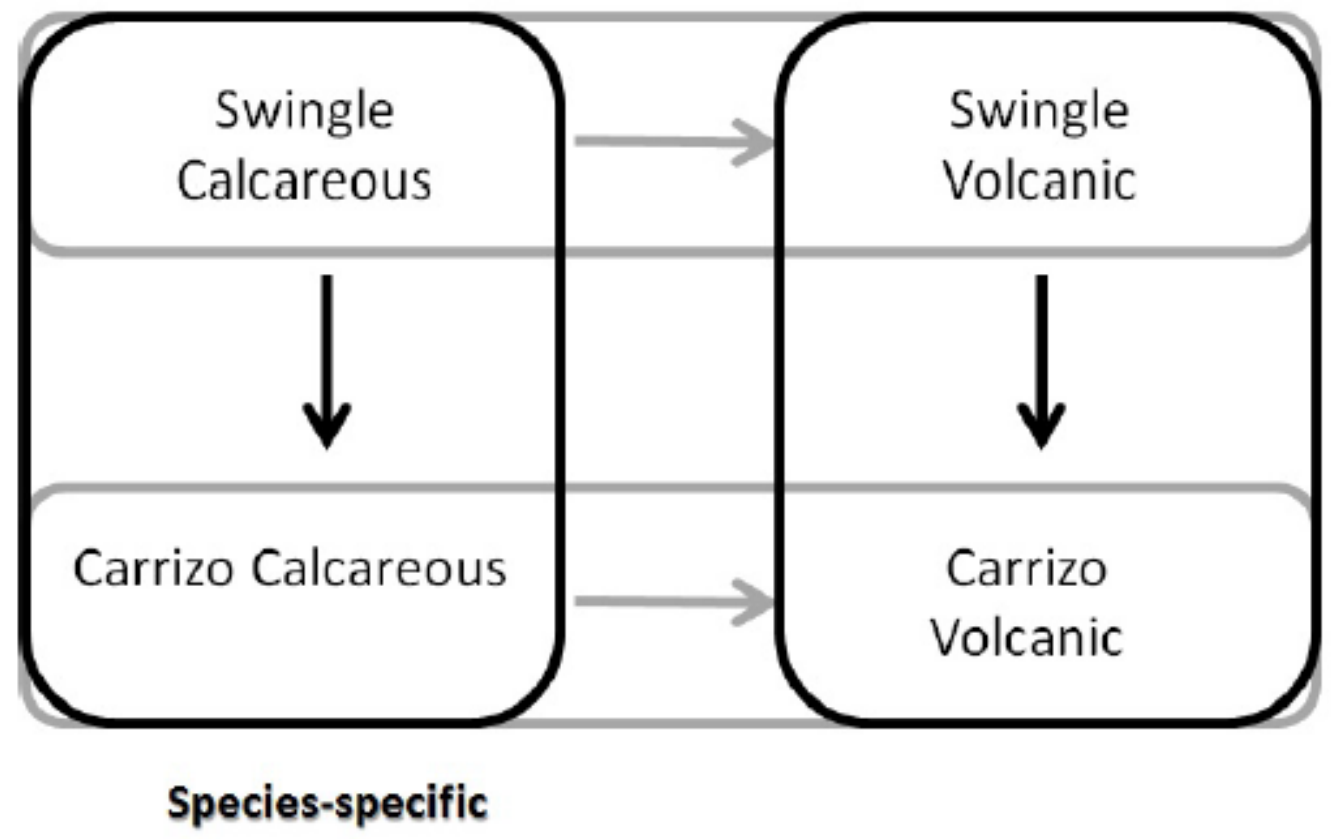

Figure 1. Experimental design for the transcriptomic and proteomic approach. 


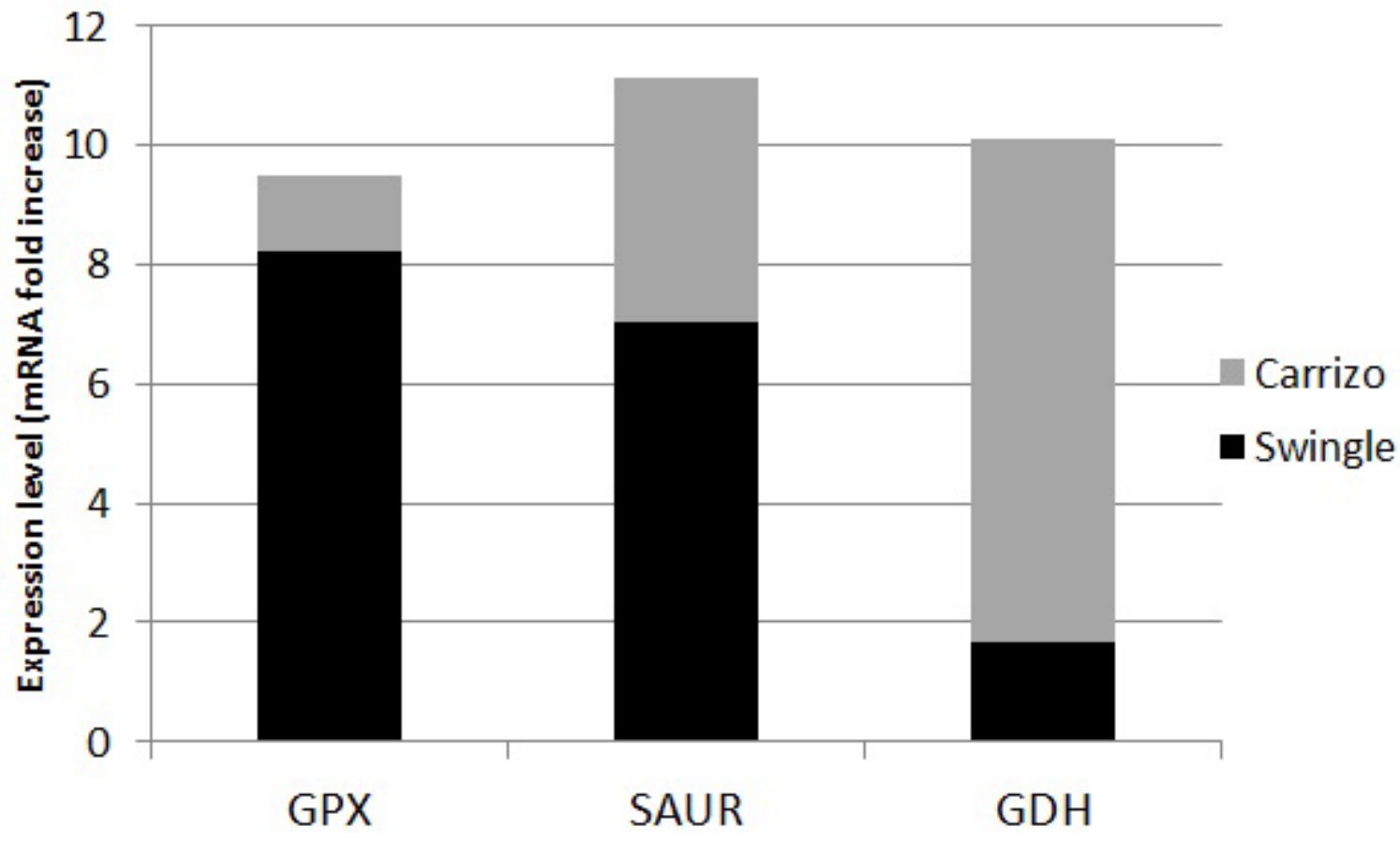

Figure 2. Expression data related to Real time RT-PCR performed on GPX, SAUR and GDH genes in tip roots of Carrizo and Swingle. 

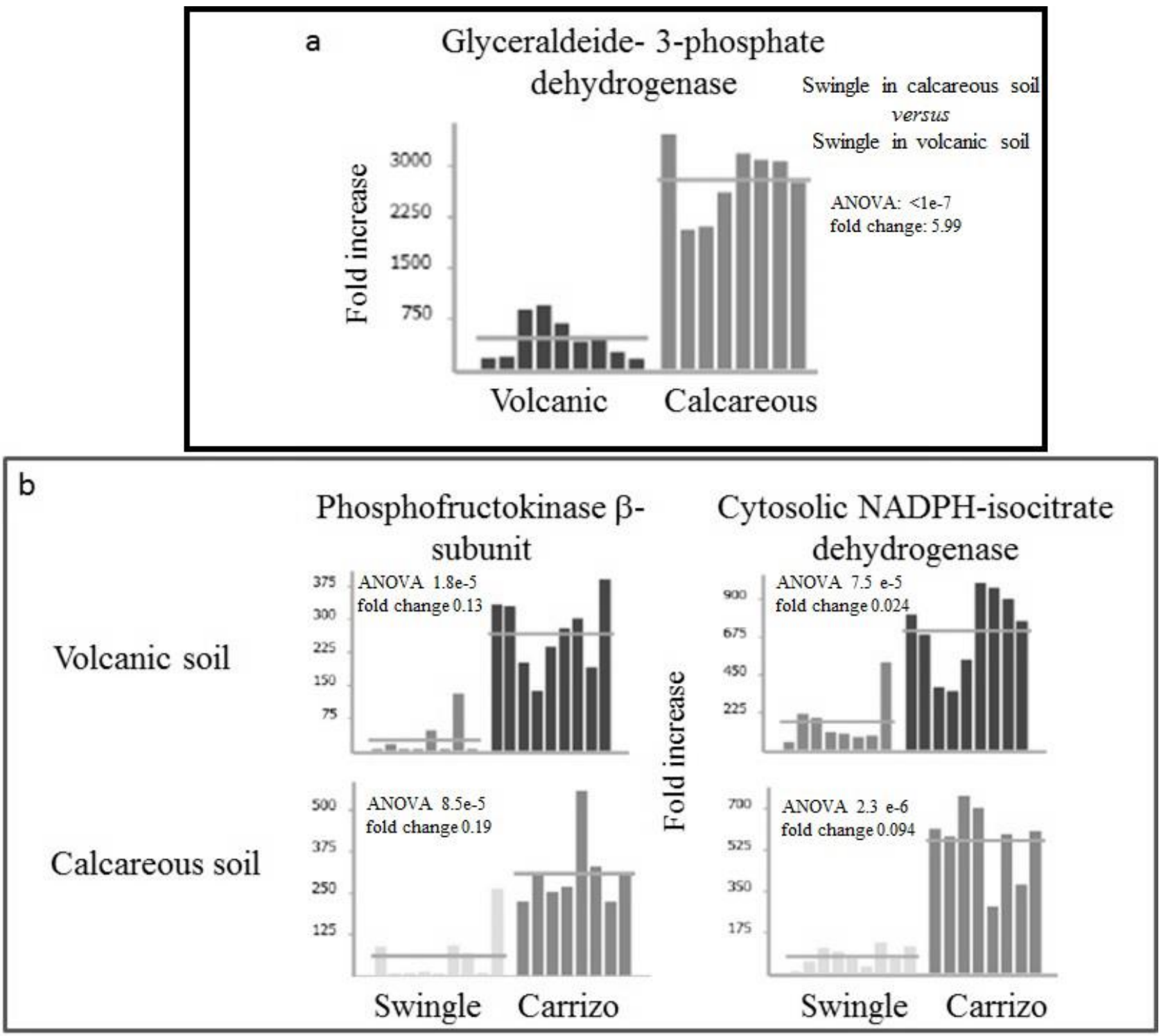

Figure 3. Significant quantitative changes in spots identified as (a) glyceraldeide-3-phosphate dehydrogenase in Carrizo under volcanic and calcareous conditions, and (b) phosphofructokinase $\beta$ subunit and cytosolic NADPH-isocitrate in Swingle and Carrizo under volcanic and calcareous conditions. 

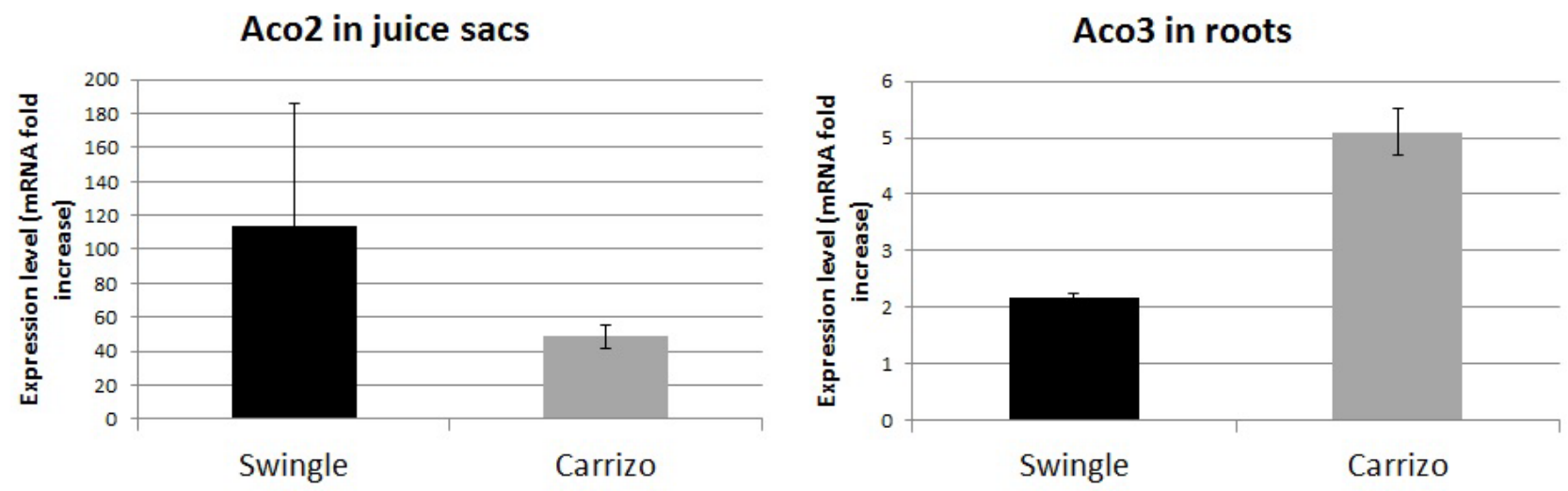

Figure 4. Expression data related to Real time RT-PCR performed on Aco2 in juice sacs and Aco3 in roots of Carrizo and Swingle. 